\title{
Kuhn e as ciências sociais
}

JESUS DE PAULA ASSIS

$\mathrm{M}$

il novecentos e noventa e dois marcou os $\mathbf{3 0}$ anos da publicação de $A$ estrutura das revoluçóes cientificas (ERC), de Thomas S. Kuhn. O objetivo primeiro do livro era o de fornecer um quadro convincente de como se desenvolvem as ciências naturais. Porém, o alcance do texto foi muito maior. Poucos anos depois de publicado, seus principais termos - notadamente paradigma e cilncia normal - já eram empregados, quase nunca no sentido pretendido pelo autor, em textos sobre artes, psicologia e ciências sociais.

A importação de termos, na verdade já mal definidos na própria origem, causou mais confusáo que resultados positivos. Kuhn não se atém a uma só acepção para cada um deles e essa multiplicidade de sentidos, somada a outros fatores como a aparente acessibilidade do livro quando comparado a outros textos de filosofia da ciência (especialmente os produzidos na esteira do positivismo lógico) e a uma certa necessidade permanente que as ciências humanas têm de se afirmar como ciências, levou a uma literatura perdida em detalhes técnicos e alheia às principais questóes levantadas pelo autor.

O objetivo deste texto é examinar os motivos que levaram historiadores e autores em epistemologia das ciências sociais a importar os termos kuhnianos de forma tão pouco fiel às intençóes do autor da ERC. Antes, será preciso fixar os principais traços do modelo de Kuhn e, igualmente importante, estabelecer o que o modelo não é.

Nesses 30 anos, muito da literatura sobre o autor, feita fora do estrito estudo epistemológico, girou sobre questốes tais como adequar Kuhn a outros domínios que não as ciências naturais ou examinar se o modelo se aplica a fatos históricos bem documentados. Exemplos típicos dessa última preocupação são questóes do gênero: "A aceitação do darwinismo foi ou não uma transição de paradigma? "Se sim, então o modelo ganharia corroboração; se não, deveria ser reestruturado, como se se tratasse de ùm modelo dentro das ciências naturais e náo sobre as ciências naturais.

Essa literatura obscurece implicaçóes mais amplas de Kuhn, tema da última parte do texto. 


\section{Kuhn e Wittgenstein}

Em 1962, aparece, na Foundations of the Unity of Science, que servia de introduçấo ao ambicioso projeto positivista da constituiçáo de uma Enciclopédia Internacional de Ciencia Unificada, um longo artigo intitulado $A$ Estrutura das Revolufóes Cientificas. Seu autor é um físico que, progressivamente, passou da física para a história da física, para a filosofia da física e, desta, para a filosofia das ciências naturais.

O impacto do trabalho de Thomas $S$. Kuhn foi imediato, por variados motivos. Em primeiro lugar, cristalizava idéias que ocupavam o espaço da teoria do conhecimento e, mais especificamente, da filosofia da ciência na década de 50. A reação ao positivismo lógico aparecia como corolário do segundo Wittgenstein. Grosso modo, seguia-se das Investigaçôes Filosoficas que uma análise proveitosa de qualquer atividade com pretensóes ao conhecimento deveria basear-se no estudo do como essa atividade acontece e menos no estudo do porque. Em outras palavras, para melhor entender a atividade denominada ciência, mais valia entender sua prática que buscar uma fugidia estrutura lógica subjacente a toda teoria que se intitulasse científica.

Trabalhos como o de Polanyi (1958), ou mesmo de Gombrich (1960), sugeriam que a atividade cientifica (artística para Gombrich) baseava-se em uma série de princípios, os quais jamais chegavam a ser enunciados. Segundo Polanyi, toda atividade científica está impregnada de procedural knowledge, ou conhecimento que se baseia na açáo, em contraste com o conhecimento baseado em princípios expressos durante a formação do cientista, o qual denomina declarative knowledge.

Esse procedural knowledge não é outra coisa que os jogos de linguagem de Wittgenstein. Tais jogos, Wittgenstein afirma, não são, em sua maioria, ensinados explicitamente, por ostensão. São exemplos de jogos de linguagem (Wittgenstein, 1953:1-23): dar ordens e obedecê-las, descrever a aparência de um objeto ou dar suas medidas, reportar um evento, especular acerca de um evento, formar e testar uma hipótese etc. Viver dentro de determinada comunidade significa, para Wittgenstein, jogar diferentes jogos de linguagem. Dentro de uma forma de vida não cabe perguntar, portanto, como se fundamentaria uma determinada sentença, mas sim qual seu papel - dentro dos jogos de linguagem relevantes para aquela forma de vida - como promotora de açóes aceitas por todos como corretas após a enunciação da sentença em questáo. Wittgenstein, assim, resume a idéia de que a compreensão de uma dada atividade - atividade científica necessariamente inclúda (alguns dos 
exemplos do que ele chama jogos de linguagem são típicos dessa atividade, como formar e testar uma hipotese ) - deve ser procurada na descriçáo dos jogos relevantes, nas açóes que tais jogos propiciam e na construção de metáforas que permitam melhor entender esses jogos.

Nas Investigafóes Filosoficas, Wittgenstein afirma que "nossos claros e simples jogos de linguagem não são estudos preparatórios para uma futura regularizaçáo da linguagem - como se fossem uma primeira aproximação, que ignorasse fricção e resistência do ar. Os jogos de linguagem são construídos como objetos de comparafä́o que pretendem lançar luz sobre os fatos de nossa linguagem através não apenas de similaridades, mas também de dissimilaridades" (Wittgenstein, 1953:1-130, itálico nosso).

Para Wittgenstein, a construção de objetos de comparafáo dcixa claro que a filosofia não tem qualquer caráter normativo (Richard Rorty prefere classificar esse trabalho da filosofia como terapentico). Sua tarefa principal é a de esclarecimento de um dado contexto, de uma dada atividade.

O mesmo vale para Kuhn.

O projeto de Wittgenstein, além de retirar da filosofia qualquer caráter normativo, sugere também não ter tal atividade caráter sequer descritivo. A construção de objetos de comparação deve - se se pretende que tais objetos esclareçam algo sobre o mundo - levar em conta o que o mundo é, ou, pelo menos, o que se acha que ele seja. Mas nada pode garantir que tais descriçóes sejam corretas (garanti-lo seria retroceder ao positivismo). Assim, os modelos que se constroem de determinada atividade ajudam a esclarecê-la, a compreendê-la melhor, mas não podem pretender retratá-la fielmente e, muito menos, justificá-la. Nesse sentido, tem pouco cabimento usar o modelo de Kuhn como modelo para a história da ciência ou como modelo fundado ou baseado na prática científica, embora muito da assimilaçáo de Kuhn em meios externos ao debate epistemológico mais especializado se deva exatamente a essa suposta base histórica do que é proposto na ERC.

\section{O modelo de desenvolvimento científico de Kuhn}

Kuhn divide o desenvolvimento científico de uma disciplina particular em dois grandes componentes: ciência normal e revoluçáo científica. Durante os períodos de ciência normal, os cientistas concordam acerca dos fundamentos de sua disciplina e o grosso de seu trabalho se 
dá no sentido de articular esses fundamentos e de ampliar sua aplicabilidade. Já nos períodos de revolução científica, acontece o debate entre alternativas rivais, no qual os participantes de cada escola baseiam seu discurso em conjuntos diferentes de fundamentos. Logo, não existe campo neutro no qual avaliar as diferentes teorias. $O$ debate não é racional, no sentido de sempre esbarrar em questóes que não podem ser resolvidas de comum acordo entre as partes, recorrendo ambas a um foro neutro e reduzindo seus diferentes discursos a um comum, via mecanismos inteiramente lógicos.

No corpo principal da ERC está a defesa da tese de que a ciência, em períodos de transição, lança mão de pseudo-argumentações sem possibilidade de serem reduzidas a um discurso racional de regras que possa ser aceito por partidários de ontologias ou de tradiçóes de avaliação diferentes. Junto a essa argumentação de princípio, Kuhn mostrará que sua teoria gera um modelo adequado para a compreensáo de algumas transições históricas. O modelo não pretende explicar tais transiçóes, uma vez que explicar significaria recorrer a algum estrato mais fundamental e bem justificado de asserçóes e a partir dele provar, via mecanismos exclusivamente lógicos, o ponto em questáo. Kuhn descarta a existência de tal estrato privilegiado.

No decorrer da ERC, Kuhn só estudará a transição entre paradigmas. As consideraçóes do autor sobre essa transição valem, com pequenas modificaçōes, para a transição entre as fases pré-paradigmática e paradigmática de uma disciplina dentre as que se costumam chamar ciências naturais.

Uma determinada atividade com pretensóes ao conhecimento atinge a fase paradigmática quando pára de haver debate em torno de princípios. As diversas escolas que estudam determinado conjunto de fenômenos concordam com ser o enfoque de uma delas o mais promissor.

Antes desse acordo, o que existe é um debate desorganizado entre diferentes escolas, partidárias de diferentes fundamentos, baseados em diferentes ontologias e que enfocam um mal definido conjunto de problemas, cada uma a sua maneira. A certa altura, uma das escolas começa a ganhar adeptos, o que sufoca as tradições rivais. A contrapartida sociológica disso é o que Robert Merton (Merton, 1968) chama Efeito Mateus. Quanto mais se desenvolve uma escola, quanto mais adeptos ganha, maior seu potencial para desenvolver-se ainda mais através de um sistema de citaçóes e premiaçóes mútuas. Esse efeito acaba por reforçar a escolha feita. 
A partir daí, o paradigma da escola vencedora ganha aceitação geral e passa a ser base de toda a tradiçáo de estudo naquele campo. Depois disso, pode haver especialização, isto é, cada grupo de cientistas pode se dedicar a determinado conjunto de fenômenos, com diferentes grupos podendo estudar diferentes fenômenos. O que importa é todos os grupos admitirem uma ontologia comum e, mesmo estudando fenômenos diferentes, concordarem com que estes sejam manifestações das entidades catalogadas naquela ontologia aceita por todos.

Demarcar a transição é algo que só pode ser feito muito tempo depois - quando o novo paradigma já estiver razoavelmente desenvolvido -, pelo exame dos manuais com os quais são iniciados os cientistas jovens. Todos mencionam os mesmos princípios básicos, com matizes apenas de caráter didático. Começam a aparecer livros mais adiantados, visando a um público já inteirado dos princípios da teoria. Os artigos de pesquisa publicados $\mathrm{em}$ revistas tendem a se tornar mais especializados e, no dizer de Kuhn, esotéricos. Uma vez que o trabalho inicial de convencimento está feito, o cientista já náo se preocupa em ser acessível para um público maior que o estritamente ligado a sua área de interesse.

Vale lembrar que nenhuma teoria nova está de acordo com todos os fatos já conhecidos do campo que pretende explicar. Essa característica das teorias científicas é reconhecida, seja por um positivista lógico ortodoxo, seja por um filo-anarquista em epistemologia. Assim, quando a comunidade aceita um paradigma, o que ela está aceitando é, na verdade, uma promessa de resoluçăo de problemas futuros, promessa que se impóe sobre as outras com base no sucesso obtido na resolução dos problemas já examinados. Nesse sentido, pode-se também dizer que a aceitação de determinado paradigma é um fenômeno irracional: ele é aceito menos pelo que fez no passado e mais pelo que se sente ele poderá fazer no futuro. Não havendo como avaliar o rendimento de determinada teoria no futuro, a escolha de uma entre diversas alternativas deve se basear em um difuso pressentimento de que as coisas poderão vir a dar certo. As teorias perdedoras não conseguiriam despertar o mesmo sentimento na comunidade.

Uma vez que todos os participantes de uma tradição de pesquisa aceitam um paradigma que os oriente, começa a fase, chamada por Kuhn, de ciência normal. Nesse ponto, a analogia que melhor caracteriza a atividade dos cientistas é a da resolução de quebra-cabeças.

A tarefa dos cientistas é então a de melhorar os padróes de medida já conhecidos, aprimorar o cálculo das constantes da teoria, tentar am- 
pliar o campo de sua aplicação etc. Aqui, teoria e paradigma estáo sendo usados indiferentemente. Grosso modo, o paradigma contém o que a epistemologia clássica chama teoria, mais os métodos de avaliaçáo da própria teoria (não só os métodos de avaliação que se poderiam chamar propriamente científicos - margens de erro admissíveis, preferência por certos tipos de instrumentos de medida etc. -, mas, principalmente, os diferentes pesos que o cientista atribui a valores mais abstratos que usa para avaliar hipóteses, como simplicidade, harmonia etc.). Classicamente, estes últimos deveriam ficar de fora das modas científicas, deveriam ser parte do foro neutro para debate entre teorias rivais. Mas isso náo acontece no modelo de Kuhn. Cada paradigma carrega consigo seus próprios métodos de avaliaçáo, o que torna impossível a decisáo racional entre paradigmas rivais.

Não há razão externa, neutra, atemporal e comum a teorias rivais. Não existe, portanto, padrão que se possa chamar racional, ao qual seja sempre possível recorrer no caso de dúvida entre duas teorias propostas para explicar dado conjunto de fenômenos.

Esse trabalho eminentemente conservador do cientista leva ao que Kuhn denomina anomalias, fenômenos que se recusam a entrar na cama de Procrusto traçada pelo paradigma. Em um primeiro momento, $o$ cientista deixa essas anomalias de lado, para estudo posterior.

Essas anomalias - que, na verdade, estăo presentes desde a proposiçáo da teoria - podem não se resolver com essa pesquisa mais aprofundada. As conseqüências que essa permanência pode ter para uma teoria estabelecida dependerão, novamente, de fatores pouco afeitos ao debate racional.

No caso de um cientista de prestígio, em instituição de prestígio, estar estudando o problema há muito tempo (esse muito também não tem como ser decidido objetivamente), então passa a ser possível pensar que o paradigma já exauriu suas possibilidades e ter chegado a hora de procurar por uma nova alternativa.

Pesa também nessa decisão o fato de os envolvidos nas tentativas de resolver o problema conseguirem convencer seus pares da centralidade da questão. Se a questão é considerada periférica, sua solução poderá esperar. Mas, se a anomalia estiver na encruzilhada dos caminhos de resolução de diversos problemas dentro da atividade norteada pelo paradigma, então é hora de se pensar ou em concentrar esforços de toda a comunidade na direção de resolver o problema específico ou, então, em substituir o paradigma vigente por algum outro. 
Não há como pesar racionalmente todos os fatores a serem levados em conta na decisão de se abandonar ou náo um paradigma, via regras explicitáveis e que devam ser aceitas por todos, sob pena de acusaçăo de inconsistência ou irracionalidade para quem não as admita. Os ligados a prestígio dispensam comentário. Mas também não é possível decidir quanto é muito tempo para que um problema resista à solução, ou o quanto um problema é central dentro de uma teoria. Do ponto exclusivamente lógico, não há como definir univocamente tais questơes.

Esses fatores serem pouco afeitos ao debate racional náo quer dizer que a transiçăo de um paradigma a outro, ou a determinação do momento em que se deve começar a ver como virtualmente aceitáveis alternativas ao paradigma vigente, sejam questóes decididas de forma inteiramente irracional. De alguma forma pouco determinada explicitamente, os líderes da comunidade sabem quando é o momento de considerar seriamente outras alternativas disponíveis.

Resgatar essa sabedoria é a tarefa de uma teoria mais esclarecedora sobre racionalidade. É a tarefa de Kuhn.

O problema, para quem o seguiu até esse ponto, começa quando se quer definir o que seja mudança de paradigma. As questóes que se colocam são: como diferenciar articulaçăo de uma teoria e mudança de paradigma? A partir de que ponto, nesse trabalho - eminentemente conservador - de articulação, deve-se admitir que um paradigma foi abandonado em prol de outro? Respostas a essas questóes exigem um exame mais rigoroso de o que seja, para Kuhn, um paradigma e do que ele entende por incomensurabilidade entre teorias, conceito que tem papel central no tópico da escolha entre teorias rivais.

O termo paradigma, em sua acepçáo primeira (como assinalado no Oxford English Dictionary, 1a ed., v.7. p.449), quer dizer exemplar: "A pattern, exemplar, example. An example or pattern of the inflexion of a noun, verb or other inflected part of speech!"

Embora seja essa a noção adotada por Kuhn, ele mesmo não lhe foi muito fiel no decorrer da ERC.

O primciro trabalho importante a separar em grupos as diferentes acepçóes em que Kuhn utiliza a palavra foi feito por Masterman (1970). Depois de levantar 21 usos diferentes do termo dentro da ERC, Masterman os dividiu em três categorias:

- Metaparadigmas ou paradigmas metafísicos. 
- Paradigmas sociológicos. Dizem respeito mais à natureza da aceitação que às características estruturais de um corpo de doutrina.

- Artefato ou construto. Essa é a acepção preferida de Kuhn, e que ele chama excmplar, querendo dizer sucesso científico reconhecido pela comunidade, que passa a ser usado analogicamente. $O$ exemplar ou artefato, ou construto - é um provedor de analogias para a comunidade de praticantes. É o exemplo de sucesso que guiará novas aplicaçôes da teoria.

Em termos hierárquicos, pode-se dizer que metaparadigma significa crença profunda, por exemplo, em que toda hipótese deve se permitir julgar pela experiência ou em que explicaçóes devem exibir estrutura lógica (ainda que não rigorosa e explicitada). É a maneira mais abrangente como se pode entender o termo.

No nível seguinte, situa-se o paradigma sociológico. Sáo os fatores que mantêm coesa determinada comunidade de praticantes de uma disciplina. Kuhn chama a esses fatores coletivamente de matriz disciplinar (embora não no corpo principal da ERC; matriz disciplinar é expressẩo usada pela primeira vez no Posfácio à ERC), e inclui generalizaçócs simbólicas, crenças e valores.

Mais na superfície - e mais próximo da atividade cotidiana do cientista -, está o exemplar, ou as realizaçóes científicas concretas da comunidade. São elas que servirão de modelo para os praticantes tentarem estender o paradigma a casos novos.

Outro ponto que Kuhn irá refinar em artigos posteriores diz respeito à questão da incomensurabilidade. Duas teorias $\mathrm{T} 1 \mathrm{e}$ T2 são ditas incomensuráveis se não há foro comum para que se decida em favor de $\mathrm{T} 1$ em detrimento de $\mathrm{T} 2$ ou vice-versa. À primeira vista, a questáo parece trivial, dado o modelo de Kuhn. Se dois paradigmas diferentes representam não apenas teorias diferentes, mas métodos de experimentação diferentes, valorações diferentes dos resultados, enfim, formas de vida diferentes, segue-se diretamente que dois paradigmas determinam dois mundos diferentes. $\mathrm{O}$ mundo definido pelo paradigma $\mathrm{Pl}$ apresenta uma ontologia $\mathrm{O} 1$, diferente da ontologia $\mathrm{O}_{2}$ determinada pelo paradigma P2.

A tese da incomensurabilidade de dois paradigmas afirma apenas que não existe foro final para a decisão entre paradigmas diferentes. $A$ observação não é neutra $\mathrm{e}$, assim, partidários de paradigmas distintos travam um diálogo de surdos (Kuhn, 1970:131-133, em conexão com o 
debate entre químicos partidários da lei das proporçōes fixas e seus adversários, em fins do século XVIII).

Kuhn (1982:670) define a questão: "Aplicado ao vocabulário conccitual que se desenvolve no interior e em torno de uma teoria científica, o termo incomensurabilidade funciona metaforicamente. A frase sem medida comum torna-se sem linguagem comum. Afirmar que duas teorias são incomensuráveis é então afirmar que não existe nenhuma linguagem, neutra ou de qualquer outro tipo, à qual ambas as teorias, concebidas como conjuntos de enunciados, possam se traduzir sem resto ou perda." (sublinhado nosso)

Sem resto ou perda é a chave para a questáo da incomensurabilidade tal como Kuhn a entende. Nenhuma teoria pode, usando somente seu vocabulário, pretender traduzir inequivocamente os enunciados de outra teoria. São possíveis traduções parciais - justamente as que permitem comparação e debate entre escolas. Mas essas traduçóes sempre deixam algo de fora. Existem termos que não têm equivalente na outra teoria.

Para que incomensurabilidade não se confunda com incomunicabilidade, Kuhn (1982:670-671) formula o conceito de incomensurabilidade local: "A maioria dos termos comuns às duas teorias funciona da mesma forma em ambas; seus significados, quaisquer que sejam, se preservam; sua tradução é simplesmente homófona. Surgem problemas de tradução apenas para um pequeno subgrupo de termos (que usualmente se interdefinem) e para os enunciados que os contêm (...) Chamarei incomensurabilidade local essa versão mais modesta da incomensurabilidade."

Mas essa definição de incomensurabilidade local é apenas uma explicitação de algo que já está contido no corpo da ERC. "(...) os proponentes de paradigmas competidores praticam seu trabalho em mundos diferentes (...) Praticando em mundos diferentes, os dois grupos vêem coisas diferentes quando olham para o mesmo ponto, na mesma direção (...) antes que eles possam esperar comunicar-se completamente, um grupo ou o outro deve experimentar o que vimos chamando de mudança de paradigma" (Kuhn, 1970:150).

A passagem deixa claro que Kuhn jamais defendeu algo como incomensurabilidade total entre teorias. No entanto, dada talvez a novidade de sua formulaçáo, uma expressáo - hoje - tấo clara como comunicar-se completamente passou despercebida de seus críticos. E não apenas de críticos contemporâneos à publicação da ERC. Laudan (1990:122) usa esta mesma passagem para justificar que "nos primeiros 
escritos de Kuhn c Feyerabend pode-se encontrar a defesa de que nenhuma afirmação dentro de um paradigma faz sentido em outro" .

Para resumir. $O$ modelo de Kuhn de desenvolvimento das ciências naturais afirma:

- a maior parte do trabalho do cientista natural se dá na fase de ciência normal, atividade orientada por um paradigma do qual o cientista está seguro. Seu trabalho é no sentido de estender esse paradigma a casos novos e de aumentar a precisão do paradigma;

- esse trabalho pode levar a problemas de difícil solução. Alguns desses problemas, no entanto, já eram reconhecidos desde que o paradigma foi aceito;

- dependendo do julgamento da comunidade quanto ao problema de difícil solução - isto é, dependendo de quem forem os membros dessa comunidade que tentaram resolvê-lo sem sucesso e do grau de centralidade que a questáo assuma para ela - , o problema poder vir a ser considerado uma anomalia;

- a resoluçáo dessa anomalia pode se dar através do paradigma vigente ou da adoção de outro paradigma. Caso valha a segunda alternativa, a escola que propóe esse novo paradigma deve convencer seus pares năo apenas de a soluçáo ser adequada, mas de o novo paradigma poder oferecer mais no futuro que seu oponente mais velho. Se esse trabalho de convencimento tiver sucesso, instala-se um novo paradigma.

\section{O modelo de Kuhn não é:}

- um modelo mecânico de transição entre teorias científicas. Embora exista uma seqüência temporal paradigma 1 /articulaçáo desse paradigma/anomalia/revoluçáo/paradigma 2 , náo existe como demarcar esses momentos a náo ser muito depois dos fatos. $\mathrm{O}$ modelo não pode, assim, ser usado para determinar em que grau uma determinada disciplina se encontra hoje;

- uma base de argumentação em favor da irracionalidade, do valetudo. Pelo contrário, as escolas rivais argumentam entre si, e argumentam proveitosamente. A escolha final entre teorias rivais se dá por critérios que só podem ser chamados irracionais num quadro em que razão signifique adoção rígida de regras explícitas e atemporais;

- uma proposta de fundamentaçáo do relativismo (se é que o relativismo levado ao limite possa receber, de alguma forma, fundamenta- 


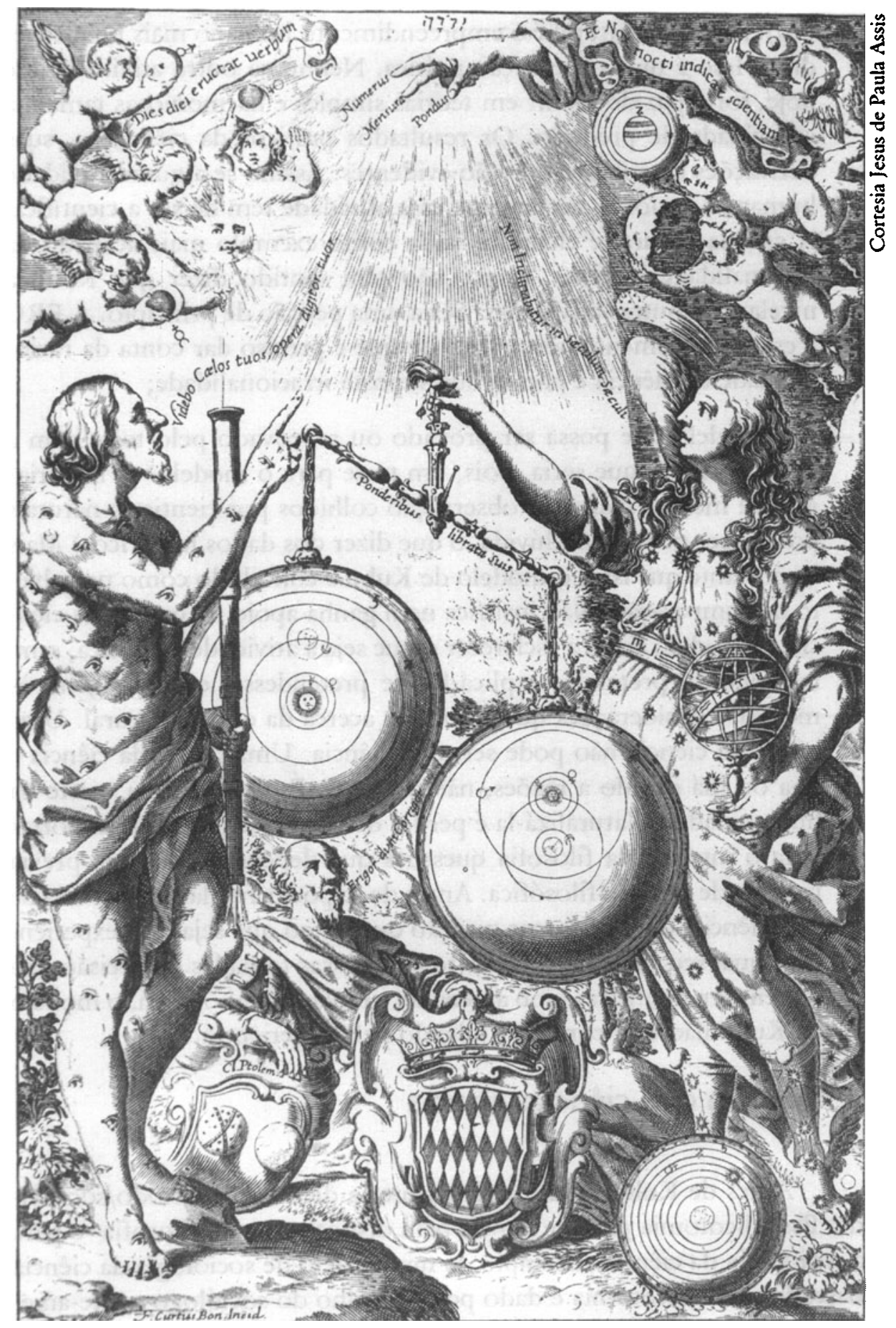

Urania avalia dois sistemas do mundo: o heliocêntrico e o geocêntrico. A gravura é de 1651 e supóe que duas teorias fisicas possam, de alguma forma, ser "pesadas " objetivamente. Essa suposiçáo segue até o século 20 e é questionada por autores como Kubn e Feyerabend. 
ção). A ciência natural é o empreendimento humano mais bem-sucedido. Isso é uma observação prática. Nenhuma outra atividade, até hoje, foi capaz de reunir em teorias simples e harmoniosas tamanha capacidade de predição. Os resultados práticos da ciência - suas derivações tecnológicas - são evidentes. Assim, se alguma atividade humana é racional, certamente essa atividade tem de ser a científica. A ciência natural é eleita de saída como exemplo mais acabado da racionalidade humana. Logo, não tem sentido dizer que Kuhn a nivela com outras atividades. Seria uma petição de princípio. A ERC é escrita justamente no espírito de que é preciso dar conta da racionalidade da ciência e não de sua suposta irracionalidade;

- um modelo que possa ser provado ou reprovado pelo teste com a experiência. O que seria, pois, um teste para o modelo? A história? Mas se mesmo dados de observação colhidos por cientistas naturais podem ser postos em dúvida, o que dizer dos dados históricos? Mais importante que isso, o modelo de Kuhn é concebido como um objeto de comparação. Não justifica nem ganha apoio da prática da ciência. O modelo ajuda a esclarecer o que seja a atividade científica, sem, no entanto, pretender explicá-la. Se pretendesse, estaria sujeito às mesmas consideraçóes que Kuhn faz acerca da ciência natural. Uma teoria da ciência nâo pode ser uma ciência. Uma teoria da ciência é boa ou má devido a razóes, não a causas. É, dessa forma, parte da humanidades. Naturalizá-la é perder de vista esse ponto. É importar para o interior da filosofia questóes que dependem de uma prévia tomada de posiçáo filosófica. Antes de se poder fundar uma teoria na experiência, deve-se tomar posição quanto ao que seja essa experiência e qual seu valor no teste de teorias. Essas tomadas de decisão náo podem ser científicas (sob a pena de circularidade). Assim, o modelo de Kuhn não tem como ser julgado pela experiência.

\section{Kuhn e as ciências sociais}

Antes de Kuhn, poder-se-ia manter a dicotomia método/sociedade. Essa dicotomia garante papéis bem distintos para a filosofia e para a sociologia da ciência. Exemplo de um modelo de sociologia da ciência baseado nessa dicotomia é dado pelo trabalho do sociólogo norte-americano Robert K. Merton.

O principal objetivo de Merton é descrever quais são as regras que normatizam a sociedade que exerce o método científico. Em Ciencia e estrutura social democrática (in Barnes, 1972:64) Merton é enfático: "Assim, consideraremos não os métodos da ciência, mas as normas com 
que são protegidos (...) Este é um ensaio sobre sociologia da ciência, não sobre metodologia" (itálico nosso).

Sociologia da ciência, portanto, é uma disciplina que estuda as normas que protegem o método. Existe uma sociedade de cientistas que protege seus princípios, os quais não são tema para o sociólogo da ciência, salvo na tarefa preliminar de delimitar essa comunidade.

Kuhn muda tal enfoque, embora esse novo enfoque em nada altere o trabalho prático do sociólogo da ciência. Este continua a fazer trabalho de campo, a levantar tendências na comunidade de cientistas, analisando, por exemplo, redes de citaçóes, crescimento e queda de institutos de pesquisa conforme os interesses de determinada política governamental, conforme modismos de origem externa ou interna à atividade científica etc. O que realmente muda é que os resultados encontrados pelo sociólogo, mais que descrever convenientemente o comportamento da comunidade científica, podem auxiliar na descrição dos métodos utilizados por ela. Assim, deixa de valer a dicotomia métodos da ciência/normas com que são protegidos usada por Merton.

As observaçóes sobre o papel decisivo que a sociologia e a história passam a ter para uma compreensão refinada do método científico devem ser tomadas com cuidado, especialmente no que tange à história.

A ênfase colocada na história não significa privilegiar o registro histórico como mais confiável que outro qualquer. A entrada em cena em papel central da história e da sociologia não deve ser vista como uma espécie de giro na direção certa na metodologia da ciência. Se assim fosse, Kuhn seria táo positivista quanto os autores positivistas que pretende combater. Ao prestar sua contribuição dentro dessa nova teoria da racionalidade científica, o sociólogo deve "... se acautelar de escapar da tentaçáo das variedades epistemológicas do mito do dado através do apelo às variedades históricas do mesmo mito" (Bernstein, 1983:74).

Finalizando o quadro traçado acima, Kuhn sabe que não há como conseguir uma compreensão adequada da racionalidade científica fazendo-se apelo a um método universal e a-histórico. $O$ melhor que se pode fazer para descrevê-la adequadamente é usar a história, "vista como mais que um repositório de anedotas ou cronologia" (Kuhn, 1970:1). Nesse ponto, entra o trabalho dos sociólogos e historiadores com suas técnicas próprias (o que Kuhn já enfatizava em 1957, na Revoluçẩo copernicana). A imagem final será, provavelmente, uma descrição mais adequada da atividade científica, mas uma descriçáo que não pode se pretender verdadeira porque teria apelado para algo supostamente mais seguro, a saber, a história da ciência. 
Ao contrário dos epistemólogos positivistas, Kuhn não está afirmando que a ciência tenha um aspecto prático - em cuja descriçáo têm papel importante tanto sociólogos quanto historiadores - e um racional, regido unicamente por leis gerais da razão, e estudado exclusivamente pela classe dos epistemólogos. Ele afirma que a Razáo (com $\mathbf{R}$ maiúsculo) é o que existe à vista. É o que pode ser recolhido nos encontros de cientistas, nos escritos publicados nas revistas científicas etc. Nâo há mais nada além disso. Náo existe qualquer estrato mais fundamental no qual seria possível tomar apoio para fundamentar essa razão eminentemente prática. Esta é só o que existe.

Dentro de tal quadro é que deve ser entendido o novo papel do sociólogo da ciência (e, talvez, não só da ciência). Náo existem, para escolha entre teorias científicas, razóes que estejam baseadas num conjunto de regras fixas. Tal conjunto inexiste para todos os fins humanos.

A ciência, na prática, não é ciência ideal + injunçôes sociais. É, simplesmente, ciencia. Ao participar das discussóes dos filósofos acerca da atividade científica, os sociólogos não estão apenas isolando fatores sociais, os quais ou protegeriam ou contaminariam uma pretensa boa ciência (e este é justamente o papel que lhes cabe dentro do quadro traçado pelo positivismo). Estáo, sim, participando de uma descriçáo da ciência tal qual ela efetivamente é. Sua contribuição, assim, não se restringirá aos fatores externos à prática científica - Merton de novo -, mas será relevante para questóes antes consideradas exclusivamente metodológicas, como critérios para escolha entre teorias rivais ou métodos de avaliação de hipóteses.

Dessa forma, Kuhn define o lugar que as ciências sociais ocupam no esforço de construir um objeto de comparação acurado para a racionalidade humana. $O$ objeto de estudo são as ciências naturais, tomadas, de saída, como as melhores candidatas ao título de atividade racional. Sobre esse objeto, debruçam-se epistemólogos, cientistas sociais, historiadores. $O$ objetivo final é a construção de um novo modelo de racionalidade. $\mathrm{E}$ só. (E já seria muito.)

Mas a ERC foi usada, um tanto surpreendentemente, como um manual para descobrir, de modo mecânico, ciências paradigmáticas ou ciências em vias de paradigmatização. Notadamente nas ciências sociais, surgiram autores que, apoiados num mal compreendido Kuhn, descobriram que elas são táo ciência quanto as ciências naturais, visto que possuem paradigmas, a despeito de a maior parte da comunidade de praticantes náo os reconhecer. Surgiram deformaçóes de sentido que pretenderam tornar a política em ciência paradigmática (Wolin, 1968), des- 
cobrir paradigmas que regem o trabalho sociológico (Friedrichs, 1972), encontrar paradigmas na religiáo (Barbour, 1974) etc.

Cabe então perguntar por que motivo terá sido a ERC usada em sentido táo diverso do pretendido por seu autor. Por que teriam epistemólogos das ciências sociais preferido usar a ERC como uma espécie de cartilha do caçador de paradigmas amador? Por que os cientistas sociais, que possuem um campo de pesquisa razoavelmente bem definido e estruturado, fundado teoricamente desde meados do século XIX, passam a aplicar o modelo de Kuhn - ou, pelo menos, o vocabulário emprestado de Kuhn - em seus textos?

Um fator a dar projeçáo especial à obra de Kuhn é sua contraposição a Popper. Outro: dada a posição de prestígio que a ciência ocupa na sociedade atual, a necessidade aparente que as ciências sociais têm de se mostrar científicas faz com que autores para os quais essa preocupaçáo é mais premente usem Kubn como seu principal apoio argumentativo.

\section{Kuhn versus Popper}

Para um empirista lógico como Nagel (1961), as ciências sociais não cumprem os cânones básicos que se espera sejam cumpridos por uma ciencia real (o modelo que ele tem em mente é a física, ou, pelo menos, uma certa idealização dela). As ciências sociais apresentariam desacordos substantivos e metodológicos e em seus textos, quando tabelas ou gráficos chegam a aparecer, serviriam mais para ilustrar um ponto que para prová-lo. (Nagel supóe que dados, de alguma forma, provam teorias ou hipóteses.)

Suposta nessa imagem está a continuidade e, portanto, cumulatividade, da ciencia real. Pois, se existe unidade metodológica e se toda hipótese é baseada em fatos, existe um foro comum para comparaçăo entre teorias: usam-se os mesmos métodos e obtêm-se os mesmos fatos que, no final, apontarão para a correção de uma entre várias hipóteses rivais. Se as ciências sociais carecem de unidade metodológica e não se apóiam sistematicamente em fatos, não há como falar em cumulatividade nem em progresso. Daí, sem poder progredir - traço essencial de uma ciencia real - sequer podem ser chamadas ciencia.

Popper não é um positivista lógico, já que nega um ponto central da doutrina positivista: a tese de que poderia existir um meio de aumentar a probabilidade de certeza de uma teoria a partir de experi- 
mentos. Mas, mesmo com essa discordância central, guarda muitos pontos em comum com os positivistas lógicos para que sua imagem possa ser bem distinguida da deles.

"Popper e Carnap assumem que a ciência natural é nosso melhor exemplo de pensamento racional (...) Ambos acham que existe uma distinçáo bem marcada entre observação e teoria. Ambos acham que o desenvolvimento do conhecimento é basicamente cumulativo (...) Ambos acham que a ciência possui uma estrutura dedutiva bem firme. Ambos sustentam que a terminologia científica é, ou deveria ser, muito precisa. Ambos acreditam na unidade da ciência (...) Ambos concordam que existe uma diferença fundamental entre contexto de justificação e contexto de descoberta" (Hacking, 1983:5).

Para Hacking, Carnap epitoma o positivismo lógico. Assim, a polêmica entre Popper e os positivistas lógicos aparece mascarada por uma superfície de acordo. As diferenças acabam sendo assunto apenas para leitores profissionais em epistemologia. Para o público que pretende tirar insights da epistemologia para sua área de estudo, os pontos em comum prevalecem sobre o ponto de discordância. Dessa forma, a polêmica mais visível na filosofia da ciência - especialmente nos anos 60 - acaba sendo Popper (=positivismo lógico) versus Kuhn.

Assim, superficialmente, Popper herda o ponto de vista positivista de que as ciências sociais ainda não são ciência, não têm unidade, não apelam para os fatos - a não ser para usá-los como ilustraçáo -, não são sistemáticas. Essas conclusóes derivariam de um modelo rígido quanto ao que pode ser admitido como científico: só proposiçóes falseáveis são científicas; quando há progresso científico - independentemente do que digam os cientistas sobre o-assunto -, há aplicação de um e único método: o método científico, que distingue a ciência de todas as outras atividades humanas; a ciência representa a meta para qual devem tender todas as atividades que pretendam conhecimento.

Kuhn aparece como alguém que aparentemente relaxa essas exigências de cientificidade e seria isso que faria dele um pensador revolucionário. Kuhn se contraporia a um Popper ditador, normativo, estreito.

"Muitos epistemólogos, e todos os popperianos, têm uma orientação normativa e não naturalista para a ciência. Aspiram a ser moralistas" (Barnes, 1982:59, itálico nosso).

Barnes faz tal afirmação em um manual de introdução à epistemologia para cientistas sociais. A questão é saber se essa imagem faz justiça a Popper. 
Popper sintetiza o método pelo qual a ciência progride: "A maneira pela qual nosso conhecimento progride, e especialmente nosso conhecimento científico, se dá através de antecipaçóes injustificadas (e injustificáveis), por palpites, por soluçōes tentativas para nossos problemas, por conjecturas. Essas conjecturas são controladas por crítica, isto é, por possíveis refutaçóes, as quais incluem testes severamente críticos (...) Se o resultado de um teste mostra que a teoria é errada, ela é então eliminada; o método de tentativa e erro é, essencialmente, um método de eliminação. Dessa forma podemos, se tivermos sorte, assegurar a sobrevivência da teoria mais apta, pela eliminaçáo daquelas mcnos aptas" (Popper, 1974:vii e 313).

Progredir em ciência significa, portanto, testar hipóteses e descartá-las em vista de experiência infirmadora. O desenvolvimento de uma ciência parece ser claramente dividido em duas fases: palpites injustificáveis (eliminando assim o problema da indução) e, depois, a pesquisa guiada por método rigoroso. Mas, em outro trecho, Popper afirma: "Com frequiência, é apenas o instinto científico do pesquisador (influenciado, naturalmente pelos resultados do testar e repetir os testes) que o leva a fazer conjecturas a respeito de quais os enunciados de $t^{\prime}$ [ $u m$ subsistema de uma teoria que está sob escrutínio] deve ele considerar inócuos e quais deve encarar como reclamando modificaçóes" (Popper, 1959:80-81).

Aqui, os palpites saem do domínio da descoberta e se esgueiram para o contexto de justificação. Desaparece, assim, uma dicotomia clara entre os dois contextos. Fatores (injustificados e injustificáveis, para usar os próprios termos popperianos) devem entrar em jogo também no momento em que uma teoria é testada, no momento em que passa por um escrutínio, em tese pelo menos, puramente racional.

O quadro desenhado pela segunda citação parece bem mais próximo da prática científica: no momento de testar determinada hipótese, o que se testa realmente é uma conjunção de proposiçóes. Nunca é o caso que uma sentença $b$ seja implicada por uma só sentença $p$. Nesse caso ideal, se $h$ se mostrasse falsa, seguir-se-ia, por modus tollens (X implica $\mathrm{Y} /$ não é o caso de $\mathrm{Y} / \mathrm{logo}$, não é o caso de $\mathrm{X}$ ), a negação de $p$. Mas $h$ é sempre conseqüente de uma implicação na qual o antecedente é uma conjunçáo de sentenças. Assim, a hipótese em teste não é " pimplica $h, "$ mas " $(p 1$ e $p 2$ e $p 3 .$. e $p n)$ implica $h "$ ". Se $h$ for infirmada pela experiĉncia, o máximo que se pode inferir é que pelo menos um componente da conjunção ( $\left.\begin{array}{lll}p 1 & \text { e... } & p n\end{array}\right)$ é falso. Determinar os componentes falsos exigiria novos testes contra a experiência e só faria o problema retornar. Uma regressão infinita é inescapável nesse caso, a me- 
nos que os cientistas compartilhem um acordo sobre onde parar de duvidar. Sem esse acordo, a prática científica é impossível.

Logo, ou existe uma inconsistência essencial no mecanismo de desenvolvimento da ciência proposto por Popper - "devo dizer que a idéia de convenção racional me choca como completamente oximorônica" (Laudan, 1990:88) - ou deve haver outra forma de interpretar seu modelo de desenvolvimento científico.

Dizer que a prática científica refuta o modelo popperiano é trivial. Nenhum cientista vai ao laboratório disposto a provar que suas hipóteses são falsas. Nenhuma teoria científica é descartada em vista de experimentos que sugiram que ela é falsa. Nenhum teste de teoria científica pode ser feito isoladamente e render resultados inequívocos.

A cumulatividade do conhecimento também não pode ser defendida facilmente. A história da ciência traz exemplos suficientes de que houve alteraçóes substanciais no conjunto de problemas estudados pelos cientistas. Tais alteraçóes não sáo apenas especializaçóes de questóes antigas (isto é, produto da subdivisão de um problema mais extenso), mas questóes radicalmente novas que jamais poderiam ser levantadas dentro da teoria superada. Mais, a história traz também exemplos de problemas que deixaram de ser reconhecidos como tais por escolas sucessivas. Se mudam os problemas, não pode haver cumulatividade na ciência, pelo menos não no sentido de aperfeiçoamento do conhecimento. Até onde o registro histórico alcança, existe apenas acumulação de resultados.

Assim, é forçoso concluir que a teoria popperiana nada tem a ver com a história da ciência ou com a ciência como ela efetivamente se dá, no dia-a-dia do cientista. Não pode, portanto, como Barnes afirma, ser normativa a esse respeito.

No dia-a-dia, no laboratório, nas discussóes com os colegas, o cientista procede através de palpites e do que Popper denomina instinto cientifico. Toda essa atividade náo pode ser racionalizada dentro de um modelo rigoroso, pois inclui inescapavelmente fatores pessoais, psicológicos, sorte, retórica etc. Dessa forma, o método popperiano, de conjectura/refutação, pode apenas ser aplicado a uma reconstrução da atividade científica.

Eis a diferença entre Popper e Kuhn se estreitando. Popper não descreve a atividade científica, não nega a importância de palpites que se poderia chamar irracionais, não dita cânones de como a atividade científica deva se conduzir. A tese popperiana se reduz a que a atividade 
científica pode, em princípio - e não pelos cientistas praticantes, mas pelos filósofos da ciência - ser reduzida à aplicaçáo de uma única regra: o processo de rcfutação de hipóteses pelo mecanismo lógico do modus tollens.

Conjectura/refutação é o método ideal da ciência (que aparece claramente apenas depois da reconstrução da prática), é a pedra de toque que reúne sob a égide de um único mecanismo toda a multiplicidade de métodos usados na prática científica.

Visto dessa forma, o sistema popperiano já parece bem menos rígido e normativo: náo diz como o cientista deve se portar, não fornece cânones de validaçáo instantânea do conhecimento (não diz ao cientista como proceder no momento da pesquisa; restringe-se apenas a uma análise retrospectiva do conhecimento supostamente obtido) e não exclui a priori qualquer área de pesquisa do domínio do que se pode chamar ciência.

Mas não é isso o que o próprio Kuhn entende ser o enfoque de Popper. "Um enfoque muito diferente de todo esse conjunto de problemas [o esclarecimento do método científico] foi desenvolvido por Karl Popper, que nega a existência de qualquer procedimento de verificação. Em lugar disso, enfatiza a importância da falsificação, ou seja, do teste que, devido a seu resultado negativo, torna necessária a rejeição de uma teoria estabelecida" (Kuhn, 1970:146).

Necessária? Tal falseacionismo ingênuo náo é aceito por Popper. Por exemplo: "Seria uma tremenda perda se, em ciência, disséssemos:

Não estamos fazendo muito progresso. Vamos nos livrar de toda ciência e começar de novo'. O procedimento racional é corrigi-la e revolucioná-la, mas não varrê-la. Você pode criar uma nova teoria, mas a nova teoria é criada a fim de resolver os problemas que a teoria antiga não resolveu" (Popper, 1974:132).

Enfim, os textos produzidos pelos empiristas lógicos são técnicos, impregnados de terminologia lógica pouco acessível e difíceis de ler por não-profissionais; os textos legíveis (Nagel é um bom e raro exemplo de equilíbrio) são severos quanto ao status científico das ciências sociais; mesmo diferindo dos empiristas lógicos em aspectos importantes, Popper, via seus pontos em comum com eles, é alinhado com essa escola e descartado com ela. Além disso, contribui para esse descarte a caracterização que o próprio Kuhn faz da obra popperiana. Uma vez que Popper é o mais destacado filósofo da ciência nos fins dos anos 50 (a Lógica da pesquisa cientifica, embora tenha sido publicada pela primeira 
vez em 1934, só foi traduzida para o inglês em 1959) e já que é supostamente refutado pelo próprio Kuhn, cria-se uma espécie de váçuo que deve ser preenchido por algum modelo de desenvolvimento da ciência. No final, o caminho está aberto para a aceitação das teses de Kuhn como contrapósição correta - isto é, que supostamente se baseia na prática da ciência - a esse Popper ingênuo e pobre de insights.

\section{A necessidade de se mostrar científico}

Por que mostrar-se científico é importante? A posição que a ciência ocupa hoje na sociedade equivale mais ou menos à da religiáo cinco séculos atrás. Dessa forma, mostrar-se científico é ganhar certificado de confiabilidade e respeito. Ficar fora do escopo do que possa merecer esse adjetivo é cingir-se ao passado, à crendice, à falta de rigor e à impossibilidade de progredir.

"A palavra [ciência] e suas variantes lingüísticas certamente não são sempre empregadas com cuidado, e são com frequiência usadas apenas para conferir uma distinçáo honorífica a uma ou outra coisa (...) Talvez, uma forma extrema de destituir o termo 'científico' de todo seu conteúdo definido seja ilustrada pelo uso cerimonioso que alguns anunciantes às vezes fazem de expressóes como 'corte de cabelo científico', - limpeza de tapetes científica' e mesmo 'astrologia científica’" (Nagel, 1961:2).

Mas Kuhn parece pôr em xeque essa posição superior ocupada pela ciência. Não que a posição não seja de facto superior. Ela o é e a observaçáo cotidiana atesta isso à exaustáo. O ponto de Kuhn é apenas que essa posição não pode ser defendida racionalmente, isso se racionalidade for entendida como aplicação de regras atemporais.

Aceito seu argumento, pareceria restar duas alternativas: dado que nem sequer a ciência pode ser justificada racionalmente, ou bem tudo pode ter pretensôes ao adjetivo científico ou nada pode tê-las.

Kuhn, desnecessário lembrar, não defenderia nenhum dos pontos. $O$ adjetivo científico tem uso prático para as atividades consagradas como ciência, que se distinguem, na prática, de outras atividades que não merecem tal adjetivo. A condecoraçáo cientifico é assunto prático $\mathrm{e}$ não lógico. É assunto que se deve decidir por apelo à história da cultura ocidental e nâo por apelo a regras metodológicas. As alternativas delineadas acima só podem ser entretidas por quem faça uma leitura estritamente normativa de Kuhn. 
A preocupação dos cientistas sociais com o status de cientificidade de sua disciplina recua, para Eckberg \& Hill (1979:129), "até Comte". Essa preocupaçáo, continuam, "implica a idéia de que o padráo segundo o qual a ciência social deve ser medida é o sucesso da ciência natural". Esse tipo de preocupaçăo traduz-se no que acima se denominou necessidade de parecer cientifico. Claro que o ideal é tornar-se cientifico, ou, como Wolin (1968) pretende, "descobrir-se científico". Mas, se esse ideal não se puder cumprir por algum motivo, serve, para início de discussáo, parecer científico.

Esse parecer não quer indicar qualquer leviandade por parte de cientistas sociais. A questáo é que, dado que os textos em ciência social - ao contrário da maior parte dos textos de ciência natural atuais - dirigirem-se a um público mais amplo que o restrito âmbito de especialistas, parecer científico cumpre a função de se destacar em meio ao painel de disciplinas que formam o conhecimento humano. Se o cientista social puder mostrar, num meio receptivo ao adjetivo cientifico, que também ele merece que o adjetivo se lhe aplique, cntão mais fácil será sobreviver num mundo em que verbas para pesquisa conseguidas em agências de financiamento detcrminam o destino de linhas de pesquisa, de pesquisadores e mesmo de departamentos inteiros.

As razões levantadas para que as ciências sociais não possam se colocar ao par de uma ciência natural bem desenvolvida, como a física, são variadas. As principais seriam:

- complexidade. Enquanto a física estuda eventos monótonos, a sociologia (ou a antropologia ou a política) estuda eventos em que intervêm fatores demais, o que torna qualquer situaçáo difícil de controlar;

- autodecepfão. Enquanto os objetos físicos não sabem o que se passa com eles, os objetos das ciências sociais o sabem. Assim, podem atuar contrariamente a suas intençôes declaradas, frustrando qualquer possibilidade de pesquisa;

- dificuldade em determinar o que seja um experimento. Enquanto em física é possível construir modelos que reproduzam características consideradas essenciais num sistema, para estudo controlado, o mesmo não pode ser feito com sujeitos humanos;

- repetibilidade. Um experimento em física pode ser repetido à vontade. Mas, numa sociedade humana, nada de análogo a um experimento pode ser feito. Não é possível repetir situações passadas. 
Contra essas objeções, o positivismo lógico apresenta argumentos tais como as encontrados em Hempel \& Oppenheim (1945) e em Hempel (1965, especialmente o capítulo 9): a física também estudaria fenômenos irrepetíveis e complexos; a questão é que ela possui um conjunto de critérios de relevância para separar o que é repetível do que é temporalmente determinado, ou seja, do que é individual. Quanto à autodecepçáo e à possibilidade de se montar experimentos, métodos estatísticos tipo duplo-cego poderiam circundar o problema.

Assim, para Hempel, a física não diferiria das ciências sociais a não ser em grau. Quando a diferença é de grau e não de qualidade, passa a ter sentido tentar atingir o grau superior na escala. Hempel dá legitimidade às pesquisas que visam a encontrar leis gerais de tipo causal para as ciências sociais e para a história.

Abraçar a alternativa sugerida pelo programa positivista tem levado a resultados decepcionantes, fato atestado pelo próprio Nagel. Mesmo Hempel não faz mais que afirmar que a história difere da física apenas em termos de grau. Não consegue ir além, para dizer o que poderiam ser leis históricas, muito menos leis sociais.

Nesse ponto, entra a leitura estreita de Kuhn. Aí, inverte-se o argumento positivista. Não é a física semelhante às ciências sociais (ou seja, não existiria entre elas apenas diferença de grau)? Kuhn não mostra - segundo essa leitura - que as ciências naturais carecem de base racional? Sim e sim. Logo, nem ciência social, nem ciência natural mereceriam logicamente o adjetivo científico. Elas estariam em pé de igualdade em termos metodológicos e, assim, ambas teriam o mesmo direito à cientificidade. Ou vale o mérito de cientifico para ambas ou para nenhuma delas. Kuhn é apresentado como o autor que mostraria que o arcabouço lógico das ciências naturais não existe, não passa de retórica ou de ideologia.

Esse uso de Kuhn toma a ERC como argumento no sentido de que a objetividade e a estrutura lógica da física seriam apenas ilusórias. Ao supostamente retirar da física as bases que ela alegava para se dizer científica, em detrimento de, por exemplo; a antropologia, Kuhn tornaria ilegítimas todas as aplicações do adjetivo cientifíco ou, o que dá na mesma, tornaria todas lícitas.

As objeçóes a esse uso da ERC podem ser encontradas diretamente em Kuhn. $O$ fato de Kuhn notar muitos pontos de contato entre ciências naturais e ciências sociais náo significa que elas não sejam diferentes de facto. Ele parte do pressuposto de que elas realmente são 
distintas. Seu ponto é apenas que dar preferência às ciências naturais na hora de atribuir o adjetivo cienttfico é algo que admite sustentação prática, mas não racional (no sentido de uma racionalidade atcmporal e formulável através de regras de aplicação universal).

Enfim, Kuhn não dá argumentos que permitam conferir cientificidade às ciências sociais (pelo menos no sentido $\mathrm{em}$ que se a atribui à física), nem subtrai cientificidade das ciências naturais. Se se quer, nas ciências sociais, parecer científico e, consequientemente, ganhar o status que $o$ adjetivo tem na sociedade atual, deve-se procurar outro apoio, mas não Kuhn.

Qual seria a raiz dessa leitura $e m$ Kuhn? Do que foi dito, deve ter ficado claro que somente uma leitura superficial e grosseira de algumas teses do autor poderia levar alguém a supor que seu modelo de desenvolvimento científico seria aplicável às ciências sociais ou, pelo menos, permitiria discutir no mesmo nível ciência natural e ciência social. Mas, de que teses do autor? Onde, nos textos de Kubn, o cientista social, ou, antes, o metodólogo da ciência social, deve buscar subsídios para classificar as ciências sociais como ciencia?

Eis algumas das teses de Kuhn sobre os primeiros estágios de uma ciência, coligidas em Laudan (1986:177):

" - fatos são colecionados ao acaso e são considerados igualmente importantes;

- existem escolas competidoras que trabalham a partir de conjuntos distintos de pressuposiçóes e que tentam minar suas rivais;

- cada escola considera fundamentais apenas aqueles fenômenos que suas pressuposiçóes podem dar conta;

- cada escola exibe o mesmo tipo de progresso que ocorre em campos completamente desenvolvidos da ciência durante períodos de desacordo acerca de pressuposiçóes;

- os resultados são apresentados em livros que desenvolvem o assunto a partir dos fundamentos e sáo endereçados tanto aos especialistas quanto ao público mais amplo."

A menos que esteja muito claro para o leitor qual o principal ponto ao qual Kuhn se refere (à crítica da reconstrução positivista da racionalidade científica) e por que Kuhn toma exemplos apenas das ciências naturais (porque parte do pressuposto de que apenas as ciências naturais são de facto reconhecidas como investigação autocrítica e progressiva - 
e é justamente o julgamento prático que lhe importa), as teses apresentadas podem sugerir que algumas outras atividades humanas - as ciências sociais, por exemplo - poderiam ser consideradas ciência subdesenvolvida.

Tome-se o caso das ciência sociais. Todas as cinco teses, hoje, se aplicam a elas. Mas isso quer apenas dizer que elas não são atividade científica (pelo menos atualmente) e jamais que elas sejam atividade pré-científica.

Uma vez que Kuhn divide as ciências naturais (seus exemplos preferenciais são a física e a química) em fases pré-paradigmática e paradigmática e, uma vez que as teses apresentadas acima (referentes à fase pré-paradigmática das ciências naturais) parecem se aplicar perfeitamente às ciências sociais tal como se apresentam hoje, uma inferência completamente imprópria justificaria a aplicação do modelo de Kuhn às ciências sociais.

As teses arroladas acima, mesmo que se ajustem a uma determinada atividade, não querem dizer que essa atividade seja pré-científica ou que poderá, eventualmente, tornar-se científica. As teses representam descriçóes do que se teria passado com atividades que hoje são, na prática, consideradas científicas, e apenas isso. As teses derivam de um escolha previamente feita quanto ao que é ciência. Não são regras metodológicas que permitiriam descobrir novos candidatos ao adjetivo cientifico.

A propósito, observe-se que, com poucas alteraçōes, as cinco teses se aplicam à culinária. Significaria isso que a culinária vive sua fase précientífica?

Mas essa idéia errônea de estágios de uma ciência ou de estágios que uma atividade deveria cumprir para se tornar ciência parece difícil dc ser erradicada. Mesmo um autor como Laudan - num artigo cujo objetivo é justamente o de arrolar as teses de Kuhn "numa linguagem relativamente livre de pressuposiçóes e idiossincrasias e sem distorcer as intençóes originais do autor" (Laudan, 1986:143) - cai na armadilha: "Num campo subdesenvolvido, advogados de um conjunto de pressuposiçóes criticam os rivais não através de apontar predições falhas, mas pelo ataque a sua plausibilidade geral. Por exemplo, a psicanálise atual e a historiografia marxista" (Laudan, 1986:193).

A tese é extraída de um artigo no qual Kuhn afirma, textualmente, que a historiografia marxista " não é ciência" (Kuhn, 1977:274). O cam- 
po subdesenvolvido corre exclusivamente por conta de Laudan. Está claro que aquilo que Kuhn se recusa a chamar ciencia se torna, mesmo para scus críticos mais perspicazes, equivalente a pré-ciencia ou ciencia subdesenvolvida. Se este é o caso com um pesquisador profissional em epistemologia, o que dizer de quem se dirige a Kuhn apenas para usar suas teses como ponto de apoio para discussóes em outros campos?

\section{Conclusão}

Pode ser que, no futuro, um modelo para o desenvolvimento e estrutura das ciências sociais venha a ser exposto e obtenha grande sucesso. Até agora, no entanto, tudo faz suspeitar que tal modelo não existe ou, se existir, pouco terá a ver com uma leitura realmente rigorosa de Kuhn. Enfim, pouco se pode esperar de Kuhn para a sociologia.

No outro sentido - ou seja, os sociólogos usando seus métodos para fazer sociologia da ciência - Kuhn é inócuo, nada tem a dizer a respeito de como deva se desenvolver tal atividade. O próprio autor enfatiza que a compreensáo da ciência cresce quando historiadores usam seus próprios métodos. Com isso, quer dizer, certamente, métodos diferentes dos usados nas ciências naturais, ou seja, métodos que não são os usados nos campos abrangidos pelo estudo feito na ERC.

Kuhn não diz como as ciências sociais (e as humanidades) poderiam tornar-se ciência c também não diz que isso poderia ser sequer interessante ou útil.

A disseminação da ERC fora dos círculos filosóficos se deve, primeiro, à retórica dc Kuhn, que produz um livro facilmente assimilável por um amplo espectro de público. Em segundo lugar, a ERC aparece numa era de contestação, numa época de decepção com a ciência, numa época de valorização do relativismo. Em terceiro, Kuhn é adotado por muitos cientistas sociais por oposiçáo a uma caricatura de Popper.

Em suma, Kuhn acaba sendo adotado (ou criticado) pelo que tem de subsidiário. Não está em questão para cle o que seja ciência, quais exatamente seus métodos, como separá-la de outras atividades ditas racionais etc. Essas questóes são todas dadas na prática. O objeto principal de Kuhn - e de outro autor importante nessa esteira, Feyerabend - é criar uma imagem convincente - um bom objeto de comparação - da atividade científica.

Essa preocupação kuhniana fica, talvez, mais evidente, ao se examinar Feyerabend. Boa parte de seu Contra o método concentra-se na 
obra de Galileu Galilei. É um dado indisputado que Galileu é um vencedor na ciência - e na mais sofisticada das ciências naturais. Mas, para Feyerabend, a vitória só pode ser o prêmio para um oportunista brutal. Pareceria seguir-se que Galileu - e, com ele, todos os grandes cientistas - foram oportunistas brutais.

Galileu foi um cientista natural refinado, o primeiro a equacionar eficazmente o balanço entre teoria e experimentação, autor de uma obra filosófica que permanece viva. É claro que Galileu é um perfeito exemplo de refinamento do espírito humano, jamais um oportunista brutal.

Porém, ao se manter um modelo de racionalidade no qual razáo significa aplicação rigorosa de um método a-histórico, atemporal, que deixa ao cientista como op̧̧óes lícitas apenas a capacidade de aceitar ou rejeitar proposiçóes, Galileu tem de ser classificado no rol dos oportunistas brutais. O problema, claro, náo é Galileu, mas o modelo que não dá conta de sua racionalidade. Vê-lo como ele realmente seria - ou o mais próximo que se possa pretender de uma imagem adequada - implica abandonar esse modelo.

Ninguém deve supor que o registro histórico trará apoio a esse novo modelo de racionalidade, da mesma forma como se chegou a acreditar que uma linguagem de observação livre de teoria trazia apoio para um modelo clássico de racionalidade (por clássico entenda-se o modelo adotado pelos neopositivistas e por Popper, em que a razão se apóia em regras atemporais e, em última instância, explicitáveis). A evidência histórica é também controvertida e, dessa forma, um modelo histórico de racionalidade não pretende ser a suposta via correta, através da consideraçăo da evidência histórica, em contraposição à suposta via incorreta, representada pela crença na possível neutralidade da experiência.

Feyerabend debruçou-se sobre Galileu e mostrou como o modelo de racionalidade atemporal transforma o melhor do espírito humano em oportunismo brutal. Kuhn, por seu turno, debruça-se sobre algumas transições históricas (a revoluçáo copernicana, a passagem da química do flogisto para a química moderna) e mostra como o modelo clássico de racionalidade transforma esses processos - reconhecidamente progressivos na história cultural da humanidade - em conversóes irracionais.

Porém, esse modelo de racionalidade está de tal forma enraizado que, à primeira vista, parece que Feyerabend teria transformado gênios da ciência em gênios da propaganda e Kuhn, as grandes revoluçóes científicas em fenômenos irracionais. $\mathrm{E}$ foi essa leitura que despertou tanta reação contra a ERC. 
Kuhn responde - por ele e por Feyerabend - a esse tipo de crítica: "Descrever o argumento de Feyerabend como uma defesa da irracionalidade na ciência me parece não apenas absurdo, maș vagamente obsceno. Eu o descreveria, junto do meu modelo, como uma tentativa de mostrar que as teorias da racionalidade existentes não sáo corretas e que precisamos reajustá-las ou mudá-las para explicar por que a ciência funciona como o faz" (Kuhn, 1970b:264, itạ́lico nosso).

Teórico da racionalidade, Kuhn deve, para melhor estudar seu objeto, procurar em que atividades ela se manifesta de maneira mais evidente. É por isso que a ERC não se chamou a $A$ estrutura das repolufóes políticas ou $A$ estrutura das repolufóes artisticas $\mathrm{e}$ assim por diante. Chamou-se $A$ estrutura das revolufóes cientificas porque a ciência natural é a mais prestigiosa atividade humana com vistas à obtenção de conhecimento. A ciência natural é um aspecto central da cultura ocidental e uma teoria da dinâmica e da racionalidade científicas é, no fim de contas, uma teoria da cultura ou, pelo menos, do aspecto mais autocrítico e reconhecidamente progressivo da cultura. Nessa perspectiva, a demoliçăo que Kuhn promove da teoria neopositivista da racionalidade é ainda mais devastadora. Se, provado seu ponto, a visão clássica não se adaptar sequer à ciência natural - o caso-limite de racionalidade -, entáo não existe mesmo nenhuma atividade na qual valha esse modelo clássico.

Nesse sentido, pode-se dizer que os exemplos cientificos têm um certo caráter acessório dentro da ERC. Bem entendido, de um lado sáo esses exemplos que permitem melhor apreciar as falhas do modelo de racionalidade que está sendo combatido. Mas, por outro, eles foram escolhidos não por Kuhn ser um teórico exclusivo da ciência, mas por precisar dela para um projeto mais amplo. Assim, se uma teoria falhar com a ciência, falhará com tudo o mais. Se escolhesse um campo considerado mais fraco em termos de método, sempre haveria a possibilidade de se argüir que, num campo supostamente "mais racional", ainda seria possível salvar a teoria clássica. Kuhn expressa isso por omissão: não discute arte, política ou ciência social em geral. Já Feyerabend deixa claro o porquê de sua escolha de exemplos retirados à ciência: "...as ciências naturais, em particular a física e a astronomia, entram na discussáo não porque' me fascinem', como afirmaram alguns confusos defensores das humanidades, mas porque constituem a questáo a debater: foram as armas que os positivistas e os seus ansiosos inimigos, os racionalistas 'críticos' [entenda-se, Popper], aplicaram às filosofias indesejadas, e são as armas que agora os levam a abdicar" (Feyerabend, 1986:330-331).

O programa neopositivista brandiu a ciência natural contra outras 
formas de conhecimento humano, exibindo-a como atividade modelar, à qual qualquer atividade por ele dita imatura deveria aspirar. Demonstrar internamente as falhas do enfoque neopositivista da racionalidade significa usar seus mesmos exemplos, lutar com as mesmas armas que usou para, no fim de contas, mostrar o quanto esteve longe de uma imagem adequada da ciência e da razão. Kuhn usa exemplos científicos pelo mesmo motivo apontado por Feyerabend.

Portanto, o caráter acessório dos exemplos usados por Kuhn no desenvolvimento da ERC não deve ser entendido no sentido de que ele poderia tomar exemplos não-científicos para ilustrar seu argumento. A história da ciência é acessória em Kuhn à medida que aparece como ilustração e não como prova de seu ponto. A ciência é acessória em Kuhn da mesma forma que Galileu o é para Feyerabend. Ler a ERC como um livro voltado principalmente para a estrutura da ciência natural seria o mesmo que ler Contra o Método como uma biografia de Galileu.

A pesquisa empreendida por Thomas Kuhn pretende livrar a filosofia da idéia de uma razáo transcendental que necessita constantemente de legitimação e, também, livrar a filosofia de um relativismo paralisante.

Nesse empreendimento têm papel de destaque as ciências sociais. É através da análise do meios pelos quais comunidades de cientistas naturais atingem acordo acerca de métodos de investigação, métodos de validação de conhecimento, limites para aceitação de evidência, limites para alteraçóes numa rede de crenças, regras para escolha entre explicaçóes alternativas para fenômenos etc., que a filosofia pode pretender traçar um quadro do que se denomina racionalidade, entendida agora como um processo e não mais como algo estático.

O cientista social, seja antropólogo, cientista político, historiador, etnógrafo, lingüista, continua a fazer suas pesquisas como sempre fez, baseado em seus próprios métodos. Pouco importa se existe constante debate acerca de fundamentos, pouco importa se se deve ou náo chamar a sociologia de ciência (ou questóes parecidas: é a história objetiva?, tem a sociologia um paradigma? etc.), o que importa é que essas disciplinas contribuam para a criação de um objeto de comparação que elucide o que é a racionalidade ou, melhor, como é ela numa dada época.

Assim, que sentido tem aplicar o modelo de desenvolvimento científico de Kuhn às ciências sociais? Nenhum, pelo menos se se pretende aplicar o modelo de maneira inteiramente fiel. Porque Kuhn não 
está propondo um modelo que - como um modelo científico - deva ser articulado e expandido para outras áreas. Ele está propondo um modelo para a racionalidade humana e apenas usa exemplos retirados às ciências naturais por conveniência de exposiçáo.

Essa maneira de interpretar Kuhn - de encaixá-lo dentro de uma tradiçáo mais ampla de crítica à racionalidade tradicional - por um lado realça o papel que as ciências sociais têm para a filosofia e, por outro, deixa claro o porquê de as aplicaçóes de Kuhn (Wolin, Barbour, Friedrichs, entre outros) serem apenas aplicaçóes de um vocabulário pobremente entendido, que só se adapta aos fins que seus autores propóem à custa de distorçóes que tornam o pensamento de Kuhn irreconhecível.

\section{Referências bibliográficas}

a. Obras de T.S. Kuhn

The Copernican revolution. Cambridge, Harvard University Press, 1957. (organizadores)

Logic of discovery or psychology of research?, 1970a. In Lakatos \& Musgrave (org.), Criticism and the growth of knowledge, 1970.

Reflections on my critics, 1970b. In Lakatos \& Musgrave, op.cit., 1970.

The structure of scientific repolutions. Chicago, University of Chicago Press, 1970.

The essential tension - selected studies in scientific tradition and change. Chicago, University of Chicago Press, 1977.

Commensurability, comparability, communicability. Philosophy of Science Association, 2, 1982, p. 669-688.

Rationality and scientific choice. The Journal of Pbilosophy, 80, 1983, p. 300-312.

What are scientific revolutions? In: Lorenz Kruger, Lorraine Daston \& Michael Heidelberger, (ed.), The probabilistic revolution, v. 1: Ideas in history. Cambridge, The MIT Press, 1987, p. 7-22.

b. Outras obras

BARBOUR, Ian. Paradigms in science and religion, 1974. In Gutting (cd.) Paradigms and revolutions - applications and appraisals of Thomas Kubn's philosophy of science, 1980, p. 223-245.

BARNES, Barry. Paradigms - scientific and social. Man, 4, 1969, p. 94-102. 
(ed.) Estudios sobre sociologla de la ciencia. Trad. Néstor Míguez. Madrid, Alianza Editorial, 1980.

Press, 1982.

T.S. Kubn and social science. New York, Columbia University

BERNSTEIN, Richard. Beyond objectivism and relativism. Oxford, Basil Blackwell, 1983.

BRYANT, Christopher G.A. Kuhn, Paradigms and Sociology. British Journal of Sociology, 26, p. 354-359.

ECKBERG, Douglas \& HILL, Jr., Lester. The paradigm concept and sociology: a critical review, 1979. In Gutting (ed.) op. cit., 1980, p. 117-136.

FEYERABEND, Paul. Contra o método, $2^{\text {a }}$ ed. Trad. Octanny da Mota e Lconidas Hegenberg. Rio de Janeiro, Francisco Alves, 1985.

Ediçóes 70, 1991.

Adeus d Razfio. Trad. Maria Georgina Segurado, 1986. Lisboa,

FRIEDRICHS, Robert W. A sociology of sociology. New York, Free Press, 1972.

GOMBRICH, E.H. Art and illusion - a study in the psychology of pictorial representation, $7^{\mathrm{a}}$ ed. Princeton, Princeton University Press, 1984.

GREENE, John. The Kubnian paradigm and the Darwinian revolution in natural history, 1971. In Gutting (ed.), op. cit., 1980, p. 298-320.

GUTTING, Gary (ed.). Paradigms and revolutions - applications and appraisals of Thomas Kuhn's philosophy of science. Notre Dame, University of Notre Dame Press, 1980.

HACKING, Ian. Representing and intervening. Cambridge, Cambridge University Press, 1983.

HEIDELBERGER, Michael. Some intertheoretic relations between Ptolomean and Copernican astronomy. In Gutting (ed.), op. cit., 1980, p. 271-283.

HEMPEL, Carl e OPPENHEIM, Paul. Studies in the logic of explanation. In Madden, Edward (ed.), The structure of scientific thought, London, Routledge \& Kegan Paul, 1960.

. Aspects of scientific explanation. New York, The Free Press, 1965.

HOLLINGER, David T.S. Kuhn's theory of science and its implications for history, 1973. In Gutting (ed.) op. cit., 1980, p. 195-222.

LAKATOS, Imre \& MUSGRAVE, Alan (org.). Criticism and the growth of knowledge. Cambridge, Cambridge University Press, 1970. 
LAUDAN, Larry. Science and relativism - some key controversies in the philasophy of science. Chicago, The University of Chicago Press, 1990.

LAUDAN, LARRY et cols. Scientific change: philosophical models and historical research. Synthese, 69, 1990, p. 141-223.

LAUDAN, Rachel. The recent revolution in geology and Kuhn's theory of scientific change, 1978. In Gutting (ed.), op. cit., 1980, p. 284-297.

MASTERMAN, Margaret. The nature of a paradigm. In Lakatos \& Musgrave, op. cit., 1970, p. 59-89.

MERTON, Robert K. Science and democratic social structure, 1942. In Barnes, B. (ed.), op. cit., 1972, p. 64-78.

Priorities in scientific discovery: a chapter in the sociology of science. American Sociological Review, v. 22, n. 6, 1957, p. 635-659.

The Matthew effect in science, 1968. Science, 159, p. 56-63.

MUSGRAVE, Alan. Kuhn's second thoughts, 1971. In Gutting (ed.), op. cit., 1980, p. 39-53.

NAGEL, Ernest. The Structure of Science, 1961. London, Routledge \& Kegan Paul, Reimpressão de 1982.

OXFORD ENGLISH DICTIONARY. James Murray, Henry Bradley, W.A. Craigie \& C.T. Onions (eds.). Oxford, Clarendon Press, 1933.

PERRY, Nick. A comparative analysis of paradigm proliferation. British Journal of Sociology, 28, 1977, p. 38-50.

PHILLIPS, Derek L. Paradigms, falsification and sociology. Acta Sociologica, 16,1973, p. 13-30.

POLANYI, Michael. Personal knowledge - towards a post-critical philosophy, 1958. London, Routledge and Kegan Paul, reimpressão de 1983.

POPPER, Karl. A logica da pesquisa cientlfica. Trad. Leonidas Hegenberg e Octanny da Mota. São Paulo, Cultrix/EDUSP, 1975.

Paul, 1974.

SHAPERE, Dudley. The structure of scientific revolutions, 1964. In Gutting (ed.), op. cit., 1980, p. 27-38.

The paradigm concept. Science, 172, 1971, p. 706-709.

STEPHENS, Jerome. The Kuhnian paradigm and political inquiry: an appraisal. American Journal of Political Science, 17, 1973. p. 467-488. 
WITTGENSTEIN, Ludwig. Philosophical investigations, 1953. Trad. G.E.M. Anscombe. London, Basil Blackwell, 2ed. revista, 1958.

WOLIN, Sheldon. Paradigms and political theories, 1968. In Gutting (ed.), op. cit., 1980, p. 160-191.

ZIMAN, John. An introduction to science studies - the pbilosopbical and social aspects of science and teclonology. Cambridge, Cambridge University Press, 1984.

\title{
Nota
}

Neste artigo são apresentados os resultados principais da dissertação de mestrado do autor, orientada pelo Prof. Dr. José Jeremias de Oliveira Filho.

\section{Resumo}

No texto, são expostos os motivos básicos pelos quais o vocabulário emprestado de Thomas Kuhn - notadamente o termo paradigma - e o modelo de desenvolvimento cientifico exposto pelo autor $\mathrm{em} \operatorname{seu} A$ estrutura das revoluffós cientificas foram tomados de empréstimo em textos que discutem a epistemologia das ciências sociais. A conclusão é que as supostas aplicaçōes do modelo kuhniano às ciências sociais se baseiam em leitura que não encontra qualquer apoio no autor e, principalmente, obscurecem as implicaçóes mais amplas de sua obra.

\begin{abstract}
The article shows for what reasons the vocabulary and the model for scientific growth of Thomas Kuhn were borrowed by epistemologists of the social sciences. The conclusion is that the texts produced in this vein are based in a shallow understanding of the author's main implications.
\end{abstract}

Jesus de Paula Assisé bacharel em Física pelo Instituto de Física (IF) da USP e mestre em Sociologia pela Faculdade de Filosofia, Letras e Ciências Humanas (FFLCH) da USP. De 1987 a 1988 foi professor da Universidade Estadual de São Paulo (Unesp-Campus de Marília). Atualmente é aluno de doutorado no Departamento de Sociologia da FFLCH-USP e diretor da sucursal de São Paulo da revista Ciência Hoje, da Sociedade Brasileira Para o Progresso da Ciência (SBPC). 